\title{
Evaluation of Acromio-Axillary-Suprasternal Notch Index in Predicting Difficulty in Visualization of Larynxs in Adult Patients
}

\author{
Vijay C. Chandak1ㅗ Nitin Rajendra Alaspurkar², Amol Singam³ \\ 1, 2, 3 Department of Anaesthesia, JNMC, Sawangi, Wardha, Maharashtra, India.
}

\section{ABSTRACT}

\section{BACKGROUND}

In medical specialty, expertise in airway management is essential. Maintaining the airway and providing oxygenation is the responsibility of the anaesthesiologist. He is also responsible for reducing the morbidity, and mortality related to difficult intubation. To reduce the risk associated with difficult visualization of larynx, preoperative assessment of airway is required. To protect patient's airway, endotracheal intubation is the gold standard. Direct laryngoscopy easily enables the securing the airway. This study was for predictive validity of the current system called acromio-axillo-suprasternal notch index in the assessment of difficult airway management.

\section{METHODS}

A total of 60 adult patients, of either gender, aged 18 - 65 years, of ASA class 1 and 2, undergoing elective surgery under general anaesthesia requiring tracheal intubation participated in this prospective, comparative, observational study. AASI was used for preoperative assessment of airway. Sensitivity, and specificity were calculated for AASI. In this study, data analysis was done using chi- square. $p<0.05$ was considered statistically significant.

\section{RESULTS}

Difficult Visualization of Larynx was observed in 3.6 \% [95 \% confidence interval (1.9 $-5.4 \%$ )] patients. Our study found that sensitivity and specificity were $75 \%$ and 95.7 $\%$ respectively.

\section{CONCLUSIONS}

Acromio-Axillary-Suprasternal Notch Index $(\geq 0.5)$ is a clear indicator of difficult larynx visualization with direct laryngoscopy.

\section{KEY WORDS}

Acromio-Axillo-Suprasternal Notch Index, Intratracheal / Methods, Intubation, Laryngoscopy / Methods, Predictive Value of Tests, Sensitivity and Specificity
Corresponding Author: Dr. Nitin Rajendra Alaspurkar. Department of Anaesthesia, JNMC, Sawangi, Wardha, Maharashtra, India. E-mail: nitin.alaspurkar@gmail.com

DOI: 10.14260/jemds/2020/685

How to Cite This Article:

Chandak VC, Alaspurkar NR, Singam A. Evaluation of acromio-axillarysuprasternal notch index in predicting difficulty in visualization of larynxs in adult patients. J Evolution Med Dent Sci 2020;9(42):3122-3126, $10.14260 /$ jemds/2020/685

Submission 12-07-2020,

Peer Review 08-09-2020,

Acceptance 14-09-2020,

Published 19-10-2020.

Copyright (C) 2020 Vijay C. Chandak et al. This is an open access article distributed under Creative Commons Attribution License [Attribution 4.0 International (CC $B Y 4.0)]$ 


\section{BACKGROUND}

In medical specialty, expertise in airway management is essential. Maintaining the airway and providing oxygenation is the responsibility of the anaesthesiologist to reduce the morbidity, mortality related to difficult intubation. To reduce the risk associated with difficult visualization of larynx preoperative assessment of airway is required. Anatomical abnormality of tongue, teeth, vocal cords and epiglottis may contribute to the difficult visualization of larynx or difficult laryngoscopy. The anatomical abnormalities should be considered while preanaesthetic checkup.

Various methods have been attempted for preoperative prediction of difficult intubation such as Modified Mallampati test (MMP), Thyro-Mental Distance (TMD), sternomental distance, hyomental distance ratio, intericisive distance and upper lip bite test $1,2,3,4,5$ specificities as well as sensitivity of these methods are different. But no one gives $100 \%$ sensitivity, this is relatively new criteria for difficult intubation. Laryngeal mask airways which is the supraglottic airway device plays important role in modern day practice of management of airways.

Difficult laryngoscopy means difficult larynx visualization i.e. difficult to visualize any parts of vocal cords after several attempts of laryngoscopy. ${ }^{6}$ Difficult airway is the condition where experienced anaesthesiologist faces difficulty for intubation. ${ }^{7}$ If anaesthesiologist is not able to intubate and not able to ventilate the patient it may lead to life threatening situations, to avoid such situations preoperative assessment of airway is important because inability to do so may cause cerebral damage, brain death or cardiac arrest of the patients.

To protect the patient's airway endotracheal intubation is the best method. Atlanto occipital joint mobility is an important to achieve the sniffing position of the patient. Endotracheal intubation is facilitated by direct laryngoscopy; other method includes by using fibreoptic bronchoscope tracheal intubation, intubating laryngeal mask airway. Hence, evaluation of airways; anticipating problems in ventilation or intubation is necessary. The preoperative airway assessment is done to diagnose difficult airways and readiness such as;

1) Proper facilities selection and techniques for airways.

2) Procure additional adjuvants airways.

3) When needed, involvement of experienced anaesthesiologist in management.

Preparedness and anticipation decreases disastrous events due to the difficult airways. In many studies conducted for optimal predictor of difficult tracheal intubation, it is noted that patients whose neck is deep inside the chest has more chances of Difficult Visualization of Larynx (DVL). To estimate difficult visualization of larynx, chest-arm junction portion above suprasternal notch level can be used as indicator. Some studies which are conducted earlier recorded that persons having Acromio-Axillary-Suprasternal notch Index (AASI) of more than 0.5 has a greater chance of difficult larynx visualization. The assumption of our study is that AcromioAxillary Suprasternal notch index of greater than 0.5 will predict difficult visualization of larynx. Hence, the study is planned for evaluation of the specificity, sensitivity, positive predictive values and negative predictive values of AcromioAxillary Suprasternal notch Index in difficult larynx visualization prediction.

The study aim is to predict the 'difficult larynx visualization' by measuring the relatively new method i.e., Acromio-Axillary- Suprasternal notch Index.

We wanted to measure the sensitivity, specificity, positive predictive values, negative predictive values of AcromioAxillary Suprasternal notch Index in predicting "Difficult Larynx Visualization".

\section{Review of Literature}

One of the commonest cause of the death was difficult intubation during general anaesthesia in United Kingdom during the era of 1980. In 1984 R. S. Cormack and J. Lehane 8 discussed the issues regarding difficult intubation in obstetrics patients which was related to anatomy and grading of laryngoscopic views and published their article in 'Anaesthesia'. Grades 1 to grade 4 laryngoscopic views were defined. The managements of the grade 1 may be easy where most of the glottis visible, grade 2 may be slightly difficult where only glottis posterior extremity seen, grade 3 may be fairly severe difficult portion of the epiglottis not seen and in grade 4 management of the airways may be impossible except by special method where even epiglottis is not exposed.

S. Rao Mallampati et $\mathrm{al}^{9}$ in 1985 tested his hypothesis by assessing pharyngeal structures visibility for difficult intubation in 210 number of patients at Brigham and women hospital, Massachusetts.

Same anaesthesiologist done Mallampati scoring and intubation. For pharyngeal structures visualization patient's mouth was wide opened with maximum protrusion of the tongue. By using Macintosh blade of size 3 direct laryngoscopy was done.

\section{Mallampati Scoring}

1. Class 1 - Visualization of faucial pillars, soft palate, uvula.

2. Class 2 - Faucial pillars, soft palate can be visualized, but the lower part of the tongue covered uvula.

3. Class 3 - Visualized soft palate only.

Mallampati et al claimed that difficult laryngoscopy can be predicted by pharyngeal aperture classification and therefore aid in expectation of tough intubation.

Airway structures retrospective analysis was done by G.I.T. Samsoon and J.R.B. Young10 in patients suffering from impossible or difficult intubation in years between 1982 to 1985. While the research started with patients with obstetrics, it was also expanded to non-obstetric patients. Six of the 1980 patients with obstetrics and six of 13,380 non-obstetrics patients struggled to get intubation. In non-obstetrics cases, the frequency of the failed intubation (1 in 2230) is lower than that of obstetrics cases ( 1 in 280). All were run at Portsmouth Hospital in St. Mary. All of the difficult intubation was completely unexpected and those patients had MMP scoring of class 4.

S. Pilkington et al ${ }^{11}$ produced a Mallampati photographic version of the test. It was checked at 12 weeks and 38 weeks of the gestational age in 242 pregnant women. Finding of their study was that Mallampati class rises with the gestational age and weight gain correlates as well. The research accepted idea 
of the fluid retention in pregnant patients with the complicated intubation.

The effect of obesity on intubation easiness is always challenging. It can be difficult to intubate the obese patients particularly with the thick neck circumference. T. Ezri et al ${ }^{12}$ researched the relationship of the anterior neck thickness in 50 extreme obese patients at Wolfsson Medical Centre, Israil (2003). The research incorporates measuring TMD, opening of the mouth, MMP, upper irregular teeth, reduced movement of neck, perimeter of the neck and sleep apnoea history. Nine (18 $\%)$ of 50 patients encountered laryngoscopic difficulty. Seven of the laryngoscopic difficulty cases had history of apnea while only two of the other 41 had history of apnea. Difficult laryngoscopy and Easy laryngoscopy were fully delineated by the neck diameter ( $50 \mathrm{vs} .43 .5 \mathrm{cms}$ ) and pretracheal thickness (28 vs. 17.5 )

Leopold H. J. Eberhart et $\mathrm{al}^{13}$ produced an article about Upper lip bite test in 2005 journal 'Anaesth Analg' In the test, in addition to Mallampati test, 1425 patients required to cover the upper lip with lower incisors, scoring 1, 2, 3. Then assessed grade of laryngoscopy. They summerised that both upper lip bite test and Mallampati as a single screening test were poor predictors for difficult laryngoscopy.

In 2005, Toshiya Shiga, Zen'ichiro Wajima, Tetsuo Inoue, Atsuhiro Sakamoto ${ }^{14}$ performed meta-analysis of 35 studies involving 50,760 patients in order to conformation of the facts that bedside measures in predicting patients requiring difficult intubation in patients with normal airways. From electronic databases data was obtained. The test like opening of mouth, scoring by Wilson, sternomental distance, thyromental distance were analyzed. Poor promise shown by individual test but there was some usefulness in predicting difficult intubation when combining Thyromental distance and MMP.

In 2010 M. Boutonett, V. Faitot, A. Katz, L.salomon, H. Keita ${ }^{15}$ assessed the change in the class of Mallampati before, during and after the labour in pregnant patients. At four stages The Mallampati class was evaluated- $8^{\text {th }}$ month of pregnancy, insertion of the epidural catheter, 20 minutes and 48 hours following delivery. The study included 87 pregnant women. During labour they found that, The Mallampati class increased (63 percent patients) and before 48 hours reversal of the changes not found.

In 2010, Arun kr Gupta et al ${ }^{16}$ published an article in British Medical Practitioners Journal (2010) based on their analysis of Kashmiri Papulations regarding 'difficult intubation predictors'. Predictors included movement of neck and head, short and wide neck, prognathic gradation, TMD, MMP, obesity, thyromental distance. Laryngoscopy view CL grading was reported on a group of 600 patients with ASA grade 1 and 2 . In the report the rate of the tough intubation was 3.2 percent. Evaluation of the predictive values of the predictors, specificity and sensitivity were done in relation to the CL. At the end of the study, best difficult intubation predictors were MMP, thyromental distance.

In Samsung Medical Centre, Seoul n, South Korea, W.H. Kim et $\mathrm{al}^{17}$ carried out a prospective retrospective analysis in 125 non-obese and 123 obese patients. Their aim was to determine whether intubation is more difficult in non-obese than in obese patients and effectiveness of the newer method, neck circumference ratio to thyromental distance ratio (NC / TD), for difficult intubation prediction. Factors like opening of the mouth, body mass index, MMP, difficult intubation history previously were recorded. Difficult intubation scores include various factors like number of additional personnel, number of intubation attempts, lifting force used Cormac and Lehane grading and vocal cords position. The new index has been compared with all indices developed. At the end it was concluded that in obese patients intubation is more difficult and new index i.e., NC / TC is better indicator for prediction of difficult intubation in obese patients than others.

\section{METHODS}

This is a prospective observational study conducted over a period of 2 years in the Department of Anaesthesiology JNMC \& AVBRH, Wardha after getting approval from Ethical Committee and written consent from patients.

\section{Inclusion Criteria}

1. Patient belonging to ASA grade $1 \& 2$.

2. Patient of either gender between 18 - 60 yrs., age group.

3. Patients requiring endotracheal intubation under general anaesthesia.

\section{Exclusion Criteria}

1. Patient with obvious abnormality of face, head, neck or shoulder.

2. Patient with anomaly in upper airway. (Tumour of tongue, maxillofacial tumour or fractures)

3. Recent surgery of head and neck.

4. Patients with inability to open mouth.

5. Patient's refusal.

The patients posted for elective surgeries were investigated as per protocol for preoperative liver function Test and kidney function test, blood test (haemoglobin, platelet count, differential count, total count), $x$ ray of chest and electrocardiograph.

All patients posted for surgeries underwent examination of airway during which Acromio-Axillary Suprasternal notch Index were assessed.

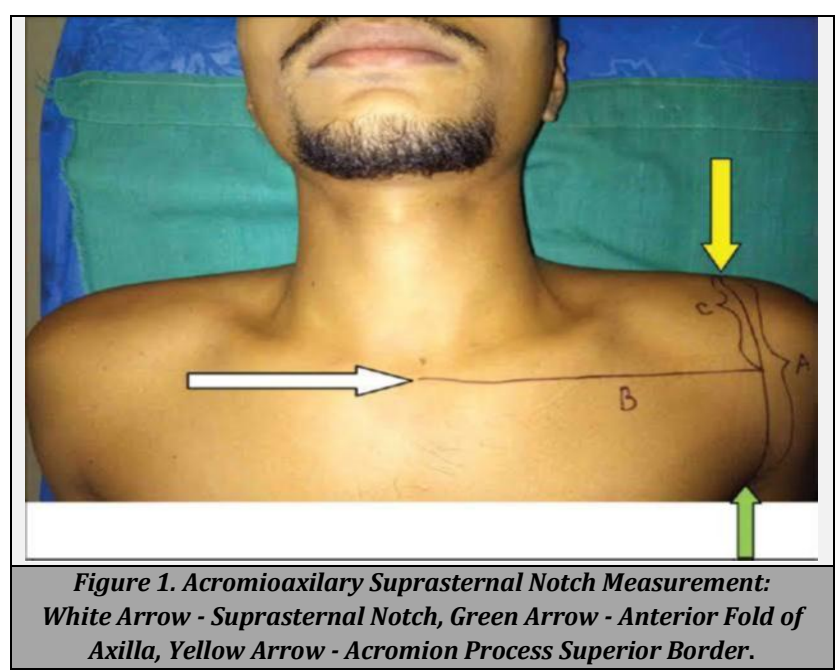




\section{Acromio Axillo Suprasternal Notch Index}

AASNI was calculated by asking the patients to lie in recumbent position with upper limbs resting by sides of body. AASI calculated based on the following measurements:

1. Line A outlined from top of acromial process to upper border of axilla using a ruler.

2. From jugular notch, line B marked perpendicular to line A.

3. Line $\mathrm{C}$ is that part of line $\mathrm{A}$ which is above intersection point of line A with line B. Acromio-Axilary Suprasternal notch Index = length of line C / length of line A (AASNI = C / A).

After evaluation of airway, patient is shifted to operation theatre and monitors like electrocardiogram, pulse oximetry (SPO2), Non-Invasive Blood Pressure (NIBP) is connected.

Before starting the procedure an intravenous (IV) line was secured and on the basis of blood sugar level of the patients' normal saline / ringer lactate solutions started.

The cart containing facial mask of all size, AMBU (Artificial Manual Breathing Unit) bag, endotracheal tube of all sizes, suction catheter of various sizes, oropharyngeal airway and nasopharyngeal airways of various sizes, laryngeal mask airways of all sizes, bougie, emergency tracheostomy tube, video laryngoscope and fibreoptic bronchoscope were kept ready.

Premedication's given to the patients includes Injection Glycopyrrolate $0.2 \mathrm{mg}$ IV, Inj. Midas $1 \mathrm{mg}$ IV, Inj. Butorphanol $1 \mathrm{mg}$ IV. Patient induced with Inj. propofol $2 \mathrm{mg} / \mathrm{Kg}$ and laryngoscopy and intubation of trachea were carried out with Inj vecuronium bromide $0.1 \mathrm{mg} / \mathrm{Kg}$ IV. Laryngoscopy was carried out by anaesthesiologist with the patient's neck flexion and upper cervical extension which is also called as sniffing neck position by using Macintosh blade of laryngoscope. For grading of the laryngoscopic view Cormack and Lehane system was used, grade 1 and grade 2 assumed as an easy visualization of the larynx and grade 3 and grade 4 assumed as a difficult visualization of the larynx.

Patient is preoxygenated with $100 \%$ oxygen for 3 minutes with ring pillow of $5 \mathrm{~cm}$ under the head. Cormac Lehane grade assessed using Macintosh blade no. 3 during direct laryngoscopy. Others measures like McCoy, laryngoscope blade 4 , bougie were used to intubate the patients whenever ETT (Endo-Tracheal Tube) insertion were difficult.

The sample size of 60 statistical analysis was carried out with open epi, open source calculator (diagnostic test) and statistical software (Statistical Package for Social Sciences). The sensitivity, specificity, Positive Predictive Value (PPV) and Negative Predictive Value (NPV) calculated for AcromioAxillary Suprasternal notch Index.

\section{RESULTS}

In our study reference data and index tests parameters of 60 patients will be presented. The demographic parameters are shown in Table 1 . There was no statistically significant difference among the difficult larynx visualization and easy larynx visualization groups in terms of demographic parameters.

\begin{tabular}{|cccc|}
\hline Variable & $\begin{array}{c}\text { Easy Visualization } \\
\text { of Laryngoscopy }\end{array}$ & $\begin{array}{c}\text { Difficult } \\
\text { Visualization of } \\
\text { Laryngoscopy } \\
\mathrm{M}=1, \mathrm{~F}=2\end{array}$ & P-Value \\
Gender & $\mathrm{M}=21: \mathrm{F}=36$ & $36+-15.55$ & 0.28 \\
Age (Yrs.) & $54+-28.28$ & $158+-2.82$ & 0.27 \\
Height (cm) & $167.5+-14.8$ & $54+-11.31$ & 0.24 \\
Weight (Kg) & $59+-7.07$ & $21.54+-2.24$ & 0.89 \\
$\begin{array}{c}\text { BMI (Kg / } \\
\text { m2) }\end{array}$ & $21.40+-1.85$ & Table 1. Demographic Characteristic of Patients \\
\hline \multicolumn{4}{r}{} \\
\hline
\end{tabular}

\begin{tabular}{|ccc|}
\hline Variables & $\begin{array}{c}\text { Number of Patients with } \\
\text { Difficult Visualization of } \\
\text { Larynx }\end{array}$ & $\begin{array}{c}\text { Number of Patients with } \\
\text { Easy Visualization of } \\
\text { Larynx }\end{array}$ \\
$\begin{array}{c}\text { Significant } \\
\text { index }(>0.5) \\
\text { Non- } \\
\text { significant } \\
\text { index }(<0.5)\end{array}$ & 6 & 7 \\
\hline \multicolumn{2}{|c|}{ Table 2. True Positive, True Negative, False Positive } \\
and False Negative Values \\
\hline
\end{tabular}

Sensitivity $(\%)=75 \%$

Specificity $(\%)=95.7 \%$

Positive Predictive Value $=46 \%$

Negative Predictive Value $=95.7 \%$

\section{DISCUSSION}

Difficult intubation and laryngoscopy if not handled properly is a major factor influencing the morbidity and mortality related to anaesthesia with irreparable sequels. Difficult intubation will be estimated in terms of Cormack Lehane (CL) grade. Anthropometry differences among the patients, different types of muscle relaxants used for intubation, differences in type of laryngoscopic blade are the main causes that are responsible for variable incidence of difficult visualization of larynx during intubation. Difficult visualization of larynx is more common in obese patients as compared to non-obese patients. There are various methods of preoperative evaluation of patient's airway such as a physical examination, detailed history and different anatomical measurements and feature.18,19 No single test exist with sufficient sensitivity and a low false positive rate to predict preoperatively the difficult intubation. ${ }^{20}$ According to Cook, difficult intubation incidences $75 \%$ in difficult laryngoscopy and $3 \%$ in easy laryngoscopy. ${ }^{20}$

In our examination AASNI have sensitivity of $75 \%$ and specificity of $95 \%$ which is can be compared to sensitivity of $81.25 \%$ and specificity of $96.7 \%$ obtained by Tejwant Rajkhowa et al. The positive and negative predictive value obtained by our study is $46 \%$ and $95.7 \%$ which is comparable to $48.15 \%$ and $99.27 \%$ respectively obtained by Tejwant Rajkhowa et al.21 Our study sensitivity, specificity is also comparable to $78.9 \%$ and $89.4 \%$ obtained by Kamranmenesh MR et al. The positive and negative predictive value is also comparable with results obtained by Kamranmenesh MR et al. ${ }^{7}$

Mohammed et al noted that sensitivity and specificity of Acromio-Axillary Suprasternal notch Index 78.9\% and 90.9 is comparable to our study sensitivity of $75 \%$ and specificity of $95.7 \%$

Various factors attributing for difficult intubation amongst the populations are dose of muscle relaxation, CL grading, protocols of intubation, position of head, cricoid pressure application, type and size of laryngoscopic blades. ${ }^{19}$ 
There are no significant differences in findings of other parameters like weight, height, and body mass index between EVL and DVL patients.

Brodsky et $\mathrm{al}^{22}$ also showed that there is no association between body mass index and difficulty in intubation.

Sometimes, estimation of AASI is possible visually and calculations are not required. Sensitivity of the diagnostic test for difficult intubation should be high with reasonably high specificity, this is the case with AASI. Though the difficulty in intubation rate is less than laryngoscopic difficulty, prediction of the difficulty in the intubation or difficult visualization of larynx lowers the risk of damages to the patients.

\section{CONCLUSIONS}

AASI is a comparatively new test that we have presented for prediction of difficult laryngeal visualization. Anaesthesiologist must recruit a number of prevailing tests as there is no single test for prediction of difficult visualization of larynx. Having siad this, several models provided using a combination of many measures, such as Wilson (movement of neck and jaw, weight, head movement, buck teeth and receding mandible), Arne (difficult intubation related disease, airway pathology clinical symptoms, difficult intubation history, mandible subluxation, and Mallampati).

Data sharing statement provided by the authors is available with the full text of this article at jemds.com.

Financial or other competing interests: None.

Disclosure forms provided by the authors are available with the full text of this article at jemds.com.

\section{REFERENCES}

[1] Chou HC, Wu TL. Thyromental distance--shouldn't we redefine its role in the prediction of difficult laryngoscopy? Acta Anaesthesiol Scand 1998;42(1):1367.

[2] Rose DK, Cohen MM. The airway: problems and predictions in 18,500 patients. Can J Anaesth 1994;41(5 Pt 1):372-83.

[3] Frerk CM. Predicting difficult intubation. Anaesthesia 1991;46(12):1005-8.

[4] Khan ZH, Mohammadi M, Rasouli MR, et al. The diagnostic value of the upper lip bite test combined with sternomental distance, thyromental distance, and interincisor distance for prediction of easy laryngoscopy and intubation: a prospective study. Anesth Analg 2009;109(3):822-4.

[5] Huh J, Shin HY, Kim SH, et al. Diagnostic predictor of difficult laryngoscopy: the hyomental distance ratio. Anesth Analg 2009;108(2):544-8.

[6] Apfelbaum JL, Hagberg CA, Caplan RA, et al. Practice guidelines for management of the difficult airway: an updated report by the American Society of
Anesthesiologists Task Force on Management of the Difficult Airway. Anesthesiology 2013;118(2):251-70.

[7] Kamranmanesh MR, Jafari AR, Gharaei B. Comparison of acromioaxillosuprasternal notch index (a new test) with modified Mallampati test in predicting difficult visualization of larynx. Acta Anaesthesiol Taiwan 2013;51(4):141-4.

[8] Cormack RS, Lehane J. Difficult tracheal intubation in obstetrics. Anaesthesia 1984;39(11):1105-11.

[9] Mallampati SR, Gatt SP, Gugino LD, et al. A clinical sign to predict difficult tracheal intubation: a prospective study. Can Anaesth Soc J 1985;32(4):429-34.

[10] Samsoon GL, Young JR. Difficult tracheal intubation: a retrospective study. Anaesthesia 1987;42(5):487-90.

[11] Pilkington S, Carli F, Dakin MJ, et al. Increase in Mallampati score during pregnancy. Br J Anaesth 1995;74(6):638-42.

[12] Ezri T, Getwirtz G, Sessler DI, et al. Prediction of difficult laryngoscopy in obese patients by ultrasound quantification of anterior neck soft tissue. Anaesthesia 2003;58(11):1111-4

[13] Eberhart LHJ, Arndt C, Cierpka T, et al. The reliability and validity of the upper lip bite test compared with Mallampati classification to predict the difficult laryngoscopy: an external prospective evaluation. Anesth Analg 2005;101(1);284-9.

[14] Shiga T, Wajima Z, Inoue T, et al. Predicting difficult intubation in apparently normal patients;a meta-analysis bedside screening test performance. Anaesthesiology 2005;103(2):429-37.

[15] Boutonnet M, Faitot V, Katz A, et al. Mallamapati class changes during pregnancy, labour and after delivery: can these be predicted? Br J Anesth 2010;104(1):67-70.

[16] Gupta AK, Mohamad O, Showkat N, et al. Predictors of difficult intubation: study in Kashmiri population. BJMP 2010;3(1):307.

[17] Kim WH, Ahn HJ, Lee CJ, et al. Neck circumference to thyromental distance ratio: a new predictor of difficult intubation in obese patients. $\mathrm{Br} \mathrm{J}$ Anaesth 2011;106(5):743-8.

[18] Türkan S, Ateş Y, Cuhruk H, et al. Should we reevaluate the variables for predicting the difficult airway in anesthesiology? Anesth Analg 2002;94(5):1340-4.

[19] Jacobsen J, Jensen E, Waldau T, et al. Preoperative evaluation of intubation conditions in patients scheduled for elective surgery. Acta Anaesthesiol Scand 1996;40(4):421-4.

[20] Cook TM. A new practical classification of laryngeal view. Anaesthesia 2000;55(3):274-9.

[21] Rajkhowa T, Saikia P, Das D. An observational prospective study of performance of acromioaxillosuprasternal notch index in predicting difficult visualisation of the larynx. Indian J Anaesth 2018;62(12):945-50.

[22] Brodsky JB, Lemmens HJM, Brock-Utne JG, et al. Morbid obesity and tracheal intubation. Anesth Analg 2002;94(3):732-6. 